Revista Eletrônica do Mestrado em Educação Ambienta1

\title{
O estabelecimento de um curso de Licenciatura em Ciências do Mar e do Ambiente na Guiné-Bissau: oportunidades, constrangimentos e desafios
}

\author{
Rui Moutinho Sá ${ }^{1}$ \\ CAPP- Centro de Investigação em Administração e Políticas Públicas| ISCSP- Instituto \\ Superior de Ciências Sociais e Políticas| Universidade de Lisboa \\ https://orcid.org/0000-0001-6407-4541
}

Resumo: Este artigo foca-se na criação de um curso de graduação em Ciências do Mar e do Ambiente na Guiné-Bissau e o contributo que tem dado para a Educação Ambiental neste país, através do ensino formal de nível superior. É apresentado um enquadramento sócio ambiental, o seu historial, bem como da sua estrutura curricular dando enfoque para as tipologias pedagógicas usadas. São também apresentadas várias atividades tanto de investigação como de extensão universitária que foram desenvolvidas no seu primeiro quinquénio de funcionamento (2014-2019) e como estas contribuíram para o seu estabelecimento tanto a nível académico como em termos de reconhecimento pelas instituições nacionais e internacionais. Por fim, são apresentadas as perceções que os próprios estudantes deste curso têm sobre o mesmo nos seus pontos fortes e limitações.

Palavras-chave: Ciências do Mar e do Ambiente, Ensino Superior, Guiné-Bissau

\section{El establecimiento de un curso de Licenciatura en Ciencias del Mar y del Medio}

\section{Ambiente en Guinea-Bissau: oportunidades, limitaciones y desafíos}

Resumén: Este artículo se centra en la creación de un curso de pregrado en Ciencias Marinas y Ambientales en Guinea-Bissau y la contribución que ha hecho a la Educación Ambiental en este país a través de la educación superior formal. Presenta un marco socioambiental, su historia, así como su estructura curricular centrada en las tipologías pedagógicas utilizadas. También se

${ }^{1}$ Pós-Doutorado em Parasitologia pela Universidade de Ciências Veterinárias e Ciências Farmacêuticas de Brno, República Checa (2014), Doutorado em Antropologia pela Universidade Nova de Lisboa e pela Universidade de Cardiff (Doctor Europaeus) (2013), Mestrado em Evolução e Biologia Humanas pela Universidade de Coimbra, Licenciado em Antropologia pela Universidade de Lisboa (2003). Investigador integrado do CAPP-Centro de Administração e Políticas Públicas do Instituto Superior de Ciências Sociais e Políticas da Universidade de Lisboa. Fundador e coordenador do curso de Ciências do Mar e do Ambiente e Diretor do Departamento de Ciências Ambientais da Universidade Lusófona da Guiné-Bissau. e-mail: ruimoutinhosa@gmail.com

Rev. Eletrônica Mestr. Educ. Ambient. Rio Grande. v. 36, n. 3. Seção especial: V Congresso Internacional de Educação Ambiental dos Países e Comunidades de Língua Portuguesa. p. 336-355. Set/Dez. 2019. 
presentan una serie de actividades de investigación y extensión universitaria que se llevaron a cabo durante sus primeros cinco años de funcionamiento (2014-2019) y cómo han contribuido a su establecimiento tanto a nivel académico como en términos de reconocimiento por parte de instituciones nacionales e internacionales. Finalmente, se presentan las propias percepciones de los estudiantes sobre este curso sobre sus fortalezas y limitaciones.

Palavras clave: Ciencias Ambientales y del Mar, Educación Superior, Guinea-Bissau

\title{
The establishment of a Marine and Environmental Sciences Degree course in Guinea- Bissau: opportunities, constraints and challenges
}

\begin{abstract}
This article focuses on the creation of an undergraduate course in Marine and Environmental Sciences in Guinea-Bissau and the contribution it has made to Environmental Education in this country through formal higher education. It presents a socio-environmental framework, its history, as well as its curricular structure focusing on the pedagogical typologies used. A number of both research and university extension activities that were carried out during its first five years of operation (2014-2019) are also presented and how they have contributed to their establishment both at academic level and in terms of recognition by national and international institutions. Finally, the students' own perceptions of this course about its strengths and limitations are presented.
\end{abstract}

Keywords: Environmental and Sea Sciences, Higher Education, Guinea-Bissau

\section{INTRODUÇÃO}

Para que os Objetivos de Desenvolvimento Sustentável tenham o sucesso e o alcance esperados em 2030 tanto a nível global (UNDP, 2016), mas sobretudo em África é importante que a economia dos países africanos assente também no conhecimento knowledge-based economy — à semelhança daquilo que é praticado pelos países desenvolvidos (ASONGU; TCHAMYOU, 2019). Desde o início deste século que vários estudos demonstram que existe uma correlação significativa e positiva entre o investimento em educação de nível superior e um crescimento no rendimento per capita dos cidadãos dos países africanos (GYIMAH-BREMPONG; PADDISON; MITIKU, 2006). O Ensino Superior pode, por isso, assumir um papel importante tanto para a economia como para a mudança e transformação social e ambiental (FILHO et al., 2018). Não obstante, e apesar de vários constrangimentos de índole epistemológica como é o caso da incorporação de conhecimentos não-hegemónicos e valorização das formas de saber tradicionais nas academias africanas que geralmente tendem a reproduzir modelos exteriores (OKOLIE, 2003) nem todos os países africanos acompanharam esta tendência de investimento no ensino superior e há alguns como é o caso da Guiné-Bissau que parece que operaram em contraciclo (LUNDY, 2018).

Rev. Eletrônica Mestr. Educ. Ambient. Rio Grande. v. 36, n. 3. Seção especial: V Congresso Internacional de Educação Ambiental dos Países e Comunidades de Língua Portuguesa. p. 336-355. Set/Dez. 2019.

E-ISSN 1517-1256 
A Guiné-Bissau é um dos países da Comunidade dos Países de Língua Portuguesa (CPLP) que apresenta um dos mais baixos Índices de Desenvolvimento Humano $(=0.455)$ ocupando a $177^{\mathrm{a}}$ posição a nível mundial (UNDP 2017). Segundo os dados mais recentes, somente $2.173 \%$ do Produto Interno Bruto (PIB) do país é alocado ao sector da Educação colocando a Guiné-Bissau na $170^{\mathrm{a}}$ posição dos países que menos investe em educação de um total mundial de 195 países (BANCO MUNDIAL, 2016). Várias têm sido as causas apontadas para esta situação como indicam SILVA e OLIVEIRA (2017, p. 22 apud LUNDY 2018, p.171) “O sistema educacional também parece ser moldado por indecisão, descontinuidades, contradições, reformas inacabadas, ineficiência, instabilidade, grandes diferenças entre áreas urbanas e rurais e não é apropriado para a realidade do país.", conjugada com uma elevada rotatividade dos responsáveis ministeriais pela Educação. Não é por isso de estranhar que o Ensino Superior na Guiné-Bissau ainda não esteja totalmente consolidado já que embora as primeiras tentativas de instituição do mesmo surjam na década de 1980 a primeira universidade do país só viria a ser criada em 1999 (SUCUMA, 2015). Por outro lado, o ensino superior na Guiné-Bissau assume também um papel de afirmação identitária como nos diz Augel (2009):

A Guiné-Bissau está ainda sem identidade nacional consolidada, com tradições culturais, lealdade étnico - locais e convicções de pertencimento muitas vezes mais claras em relação à própria comunidade étnica do que à "nação" guineense propriamente dita. É dentro de tal contexto, e tentando descortinar possíveis novas perspetivas para a Guiné-Bissau, que desejo falar da universidade e do ensino superior, falar do papel da universidade para a construção da guineidade (AUGEL, 2019, p.147).

Não obstante, a Guiné-Bissau está localizada numa das zonas mais ricas da África Ocidental detendo um rico e vasto património natural e cultural de relevância mundial (TEMUDO; FIGUEIRA; ABRANTES, 2015). Na sua ampla plataforma continental encontra-se o arquipélago dos Bijagós constituído por aproximadamente uma centena de ilhas e ilhéus. Na paisagem vários estuários altamente férteis em recursos haliêuticos que beneficiam de um encontro de correntes, águas pouco profundas e um aporte de nutrientes únicos. De destacar ainda, que na ZEE (Zona Económica Exclusiva) da Guiné-Bissau, cujo limite atual está fixado nas 200 milhas náuticas de distância à costa, há ainda a existência de recursos geológicos energéticos muito assinaláveis como é o caso do petróleo. Estimase que, em termos globais, os recursos marinhos atinjam um valor de mercado que ronda os 3 triliões de dólares por ano, cerca de 5\% do PIB mundial. Na Guiné-Bissau a 
contribuição do sector das pescas no PIB total está estimada em 7.1\% ou 6.888 mil milhões de FCFA (INTCHAMA; BELHABIB; JUMPE, 2018). Por outro lado, as principais manchas de floresta sub-húmidas do sul, com transição para as florestas secas e semi-secas no centro-norte constituem uma barreira ao avanço do deserto. No ambiente terrestre persiste ainda uma grande diversidade biológica onde se podem encontrar várias espécies de plantas, mamíferos, aves, répteis e anfibios, algumas delas ameaçadas de extinção (AUKEMA et al., 2017). Não obstante, a economia da Guiné-Bissau e a sua população humana continuam grandemente dependentes dos recursos naturais, sendo as suas principais fontes de receita: a exportação agrícola, essencialmente assente no caju; a concessão de licenças de pesca; e a exploração florestal (VASCONCELOS, 2015). Todavia, as sinergias tradicionais entre Humano-Ambiente alteraram-se e atualmente a pressão sobre os recursos finitos tem vindo a revelar-se insustentável. O aproveitamento adequado destes recursos tão diversificados necessita por isso de uma abordagem multidisciplinar, mas a aposta estratégica da República da Guiné-Bissau nos recursos marinhos e ambientais estava condicionada pela ausência de recursos humanos qualificados (SÁ 2016).

Como surgiu então o primeiro curso de graduação (i.e., licenciatura) em Ciências do Mar e do Ambiente (CMA) na Guiné-Bissau? Este artigo explica o enquadramento, as origens e o historial deste curso de formação de nível superior na Guiné-Bissau. Identifica as principais atividades de investigação e de extensão universitárias conduzidas no seu âmbito ao longo do quinquénio 2014-2019 e são apresentadas as perceções que os próprios estudantes têm sobre o mesmo e como é que ele tem vindo a contribuir para a implementação de uma Educação Ambiental integrada.

\section{ABORDAGENS METODOLÓGICAS}

A observação participante foi a técnica etnográfica a que recorri para a recolha de informação visto que durante cinco anos participei diretamente não só na coordenação do curso como fui docente do mesmo permitindo-me por isso possuir uma visão émica da sua progressão (HAMMERSLEY; ATKINSON, 2001). Recorro por isso à memória e às minhas anotações em diários de campo na primeira pessoa etnograficamente.

Para aferir as perceções que os estudantes têm sobre o curso de CMA foi igualmente aplicado um inquérito por questionário anónimo durante as primeiras semanas de Julho de 2019 através de uma amostragem por conveniência simples aos alunos dos

Rev. Eletrônica Mestr. Educ. Ambient. Rio Grande. v. 36, n. 3. Seção especial: V Congresso Internacional de Educação Ambiental dos Países e Comunidades de Língua Portuguesa. p. 336-355. Set/Dez. 2019. 
diversos níveis do curso. O questionário estava composto por trinta (30) questões: fechadas, abertas e por escalas de Likert (CHICA; COSTA, 2006) onde os alunos puderam manifestar a sua opinião sobre o curso bem como avaliar a sua qualidade pedagógica e os serviços prestados. A validação dos questionários ocorreu quando >90\% de respostas foram obtidas tendo resultado uma base de dados final com $(\mathrm{N}=78)$ entradas. A análise de estatística descritiva dos dados foi realizada recorrendo ao software Microsoft Excel.

\section{RESULTADOS E DISCUSSÃO}

\section{A génese do curso de licenciatura em Ciências do Mar e do Ambiente na Guiné- Bissau e o seu entorno sócio ambiental}

O curso de CMA surgiu oficialmente a 1 de Setembro de 2014 quando a direção da Universidade Lusófona da Guiné (ULG) me contratou para estabelecer o curso e dirigir igualmente o Departamento de Ciências Ambientais. O curso surge num contexto político de esperança. Depois do golpe de estado de 2012 a Guiné-Bissau passou por mais um período conturbado de instabilidade e transição (GEBREMICHAEL et al., 2019). No último semestre de 2014 havia por isso, um sentimento generalizado de otimismo: o novo governo liderado na altura pelo Eng. ${ }^{\circ}$. Domingos Simões Pereira e pelo novo Presidente da República José Mário Vaz recém-eleitos e ambos pertencentes ao histórico Partido Africano para a Independência da Guiné e Cabo Verde (PAIGC) gozavam de um estado de graça com bastante apoio popular. Era frequente ouvir-se nas ruas: "Ess biás Guiné lanta" $[\mathrm{Kr}]^{2}$. O país recolheu igualmente um significativo apoio financeiro por parte da comunidade internacional num evento que ficou designado por "Mesa Redonda" onde a Guiné-Bissau conseguiu obter um apoio de mais de mil milhões de Euros após a apresentação do seu programa Terra Ranka (DW, 2015). Este otimismo viria a dissipar-se quando o Presidente Vaz demitiu o Primeiro Ministro em Agosto de 2015 provocando uma crise constitucional, sucedendo-se a nomeação de seis governos num espaço de três anos entre 2015 e 2018 (KOHL, 2016). Importa referir também que o curso de CMA surge num grave contexto de crise sócio ambiental tanto a nível transnacional do ponto de vista social, como a nível interno do ponto de vista ambiental.

${ }^{2}$ Traduzido do Creoulo da Guiné [Kr] e significa: "Desta vez a Guiné vai-se levantar",

Rev. Eletrônica Mestr. Educ. Ambient. Rio Grande. v. 36, n. 3. Seção especial: V Congresso Internacional de Educação Ambiental dos Países e Comunidades de Língua Portuguesa. p. 336-355. Set/Dez. 2019. 
A nível social os alarmes mundiais começaram a soar quando os governos mundiais se aperceberam que havia o risco de infeção pelo vírus Ébola (EIV) cujo surto havia surgido na vizinha Guiné-Conacri em dezembro de 2013 e que escalou em número de ocorrências podendo vir assumir proporções de pandemia devido à incapacidade de contenção deste vírus hemorrágico altamente agressivo para os hospedeiros, como também vir a provocar muitas dificuldades do ponto de vista de resposta humanitária (PIOT; MUYEMBE; EDMUNDS, 2014). Apesar do EIV ter provocado um número muito elevado de óbitos nos países circundantes (i.e. Guiné-Conacri, Senegal, Libéria) não houve nenhum caso reportado na Guiné-Bissau, mas obrigou as autoridades governamentais e as agências internacionais a um grande esforço de prevenção (CÁCERES el al., 2016). Um dos constrangimentos observados na Guiné-Bissau era que as diferentes instituições de saúde pública, saúde ambiental e saúde animal não partilhavam recursos, meios e informações, pelo que era necessário mudar de paradigma já que o EIV se tratando de uma zoonose obrigava a uma maior sinergia a nível interinstitucional. A resposta preventiva ao Ébola tornou-se um desafio nacional e em Janeiro de 2017 foi formalizada uma Rede de Saúde Única da qual o departamento de Ciências Ambientais que eu dirigia na ULG fez parte constituinte já que era necessário envolver as instituições de ensino superior e de investigação do país (INASA, 2017).

Do ponto de vista ambiental a Guiné-Bissau sofreu graves pressões sobre a sua floresta particularmente depois do golpe de estado de 2012. Estudos do Instituto dos Recursos Mundiais baseado em Washington revelaram que a Guiné-Bissau se encontra entre os países africanos com maiores taxas de desflorestação (UNIOGBIS, 2017). Esta exploração insustentável e tráfico ilegal de madeira fez despoletar uma reação por parte da sociedade civil que se mobilizou para tentar parar desflorestação que não foi só seletiva e dirigida ao pau de sangue (Pterocarpus erinaceus) e mogno africano (Khaya senegalensis) apesar destas espécies terem sido as mais fustigadas (DW, 2014). Mesmo depois de decretada uma moratória de cinco anos pelo governo, o desmatamento e a venda ilegal de madeira continuou nos anos seguintes (DN, 2018).

Era por isso necessário criar mecanismos de educação ambiental a longo prazo para a população e o curso de CMA surge também como uma forma de resistência por via da educação superior. Neste entorno, os primeiros passos foram dados em Agosto de 2014 quando a direção da ULG se mostrou interessada em alargar a sua oferta formativa. Era, no entanto, necessário recolher opiniões e apoios institucionais. Os primeiros contactos foram estabelecidos por mim com três personalidades representantes de instituições que desde a Educação Ambiental dos Países e Comunidades de Língua Portuguesa. p. 336-355. Set/Dez. 2019. 
primeira hora abraçaram o projeto: o Doutor Alfredo Simão da Silva - Diretor Geral do Instituto da Biodiversidade e das Áreas Protegidas (IBAP), pelo Doutor Iça Barri - Diretor do Centro de Investigação Pesqueira Aplicada (CIPA) e com o Eng. ${ }^{\circ}$ Nelson Dias representante da International Union for Conservation of Nature na Guiné-Bissau (IUCN). O pedido oficial para reconhecimento e homologação do curso de Ciências do Mar e do Ambiente foi entregue à tutela- Direção Geral do Ensino Superior e Secretaria de Estado do Ensino Superior e Investigação Científica do Ministério de Educação da República da Guiné-Bissau em cumprimento com todos os requisitos necessários elencados no Art. ${ }^{\circ} 21$ da Lei $n^{\circ} 3 / 2011$ (Lei do Ensino Superior) tendo o mesmo sido tacitamente aceite. A aula inaugural do curso ocorreu no dia 07 de Janeiro de 2015 perante oitenta (80) alunos matriculados.

\section{Missão e objetivos do curso de CMA}

As motivações que estão subjacentes à criação do curso de CMA são de duas ordens: uma pessoal e outra de mercado. Realizo trabalho de investigação na Guiné-Bissau desde 2017 sobretudo no âmbito ecológico com espécies ameaçadas. Foi na Guiné-Bissau que progredi não só academicamente, mas também cientificamente (SÁ, 2011; 2013). Quando me foi lançado este desafio senti que era a minha oportunidade de retribuir ao país. Estava consciente que a longo prazo os efeitos da transmissão de uma formação sólida iriam (irão) fazer-se sentir sobretudo na mudança de atitudes, valores e práticas. Por outro lado, segundo o relatório DENARP II (2011, p.72 apud SANI; OLIVEIRA 2014, p.138):

O país é iminentemente agrícola, ainda que tradicional, e com grandes potencialidades do pescado. Porém as instituições de formação superior do país ainda não oferecem cursos, quer de agricultura, quer de pescas, áreas consideradas base da nossa economia.

De igual forma o próprio programa Terra Ranka identificou quatro principais impulsionadores para o crescimento económico da Guiné-Bissau: 1) - agronegócio; 2) pescas; 3) - turismo e, 4) - exploração transparente e sustentável dos recursos minerais (EU, 2015). A aposta estratégica da República da Guiné-Bissau estava por isso condicionada pela ausência de recursos humanos qualificados para estas áreas fulcrais.

Os principais objetivos e as competências inscritos no guia de curso são (SÁ, 2016):

Rev. Eletrônica Mestr. Educ. Ambient. Rio Grande. v. 36, n. 3. Seção especial: V Congresso Internacional de Educação Ambiental dos Países e Comunidades de Língua Portuguesa. p. 336-355. Set/Dez. 2019. 
1. Formar recursos humanos com um conhecimento atualizado, multi e interdisciplinar, que proporcione uma visão integrada dos assuntos do Mar e do Ambiente, capazes de compreender o funcionamento dos sistemas marinhos e ambientais e as suas interações com o Meio e com o Homem;

2. Providenciar uma formação sólida para uma carreira quer como oceanógrafo profissional, quer como gestor ambiental ou numa gama alargada de outros contextos profissionais (industriais, de investigação, consultoria, etc.);

3. Estimular o espírito científico e desenvolver as capacidades de observação, análise e compreensão, de modo a possibilitar a tomada de decisões com apropriado conhecimento de diversas variáveis;

4. Desenvolver competências intelectuais, pragmáticas e de trabalho de campo, relacionadas com a recolha, análise, interpretação e compreensão de dados ambientais e oceanográficos;

5. Desenvolver capacidades críticas e analíticas ao nível da resolução de problemas, especialmente relacionados com as Ciências do Mar e do Ambiente;

6. Cativar para uma aprendizagem contínua, ao longo da vida e para o reconhecimento do valor da educação e da valorização pessoal na sociedade;

Não é por isso de estranhar que as principais saídas profissionais do curso de CMA se destinem à formação de funcionários e técnicos da administração central, serviços a nível regional e administração local mas também preparar quadros para atuação em empresas públicas e privadas com atuação na área de Ciências do Mar e do Ambiente bem como em empresas de consultoria e de estudos de avaliação, impacte e gestão ambiental para além do Ensino e da Investigação Científica.

\section{Estrutura e organização curricular do curso de CMA}

De acordo com a Lei do Ensino Superior da Guiné-Bissau, os cursos de licenciatura têm de ter uma duração mínima de quatro (4) anos ou 8 semestres letivos (RGB Lei $\mathrm{n}^{\circ}$ 3/2011). Para além disso, o Conselho Africano e Malgaxe para o Ensino Superior (CAMES) recomenda que as licenciaturas devam estar harmonizadas no seu espaço para haver um maior reconhecimento multilateral dos mesmos graus académicos o que implica que uma licenciatura na Guiné-Bissau ronde as 3200 horas na sua totalidade (CHIKOUNA, 2018). O curso de CMA segue estas premissas e tem a duração de quatro anos letivos. Os dois primeiros anos do curso constituem um tronco comum onde os

Rev. Eletrônica Mestr. Educ. Ambient. Rio Grande. v. 36, n. 3. Seção especial: V Congresso Internacional de Educação Ambiental dos Países e Comunidades de Língua Portuguesa. p. 336-355. Set/Dez. 2019. 
estudantes adquirem os conhecimentos base e fundamentais e a partir do $3^{\circ}$ ano têm de optar por uma das seguintes especialidades: Gestão Ambiental ou Oceanografia e Recursos Marinhos (Fig. 1).

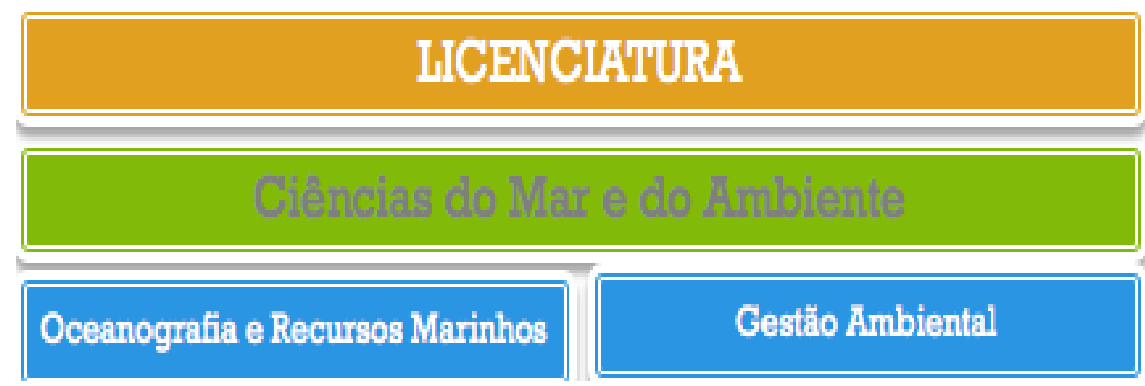

Fig. 1. Estrutura orgânica do curso de licenciatura em Ciências do Mar e do Ambiente (SÁ, 2016, p. 4).

O curso tem uma forte componente disciplinar em Ciências da Terra e da Vida, Ciências Exatas, mas também em Ciências Sociais. Na Fig. 2 podem verificar-se as respetivas proporções para cada área científica.
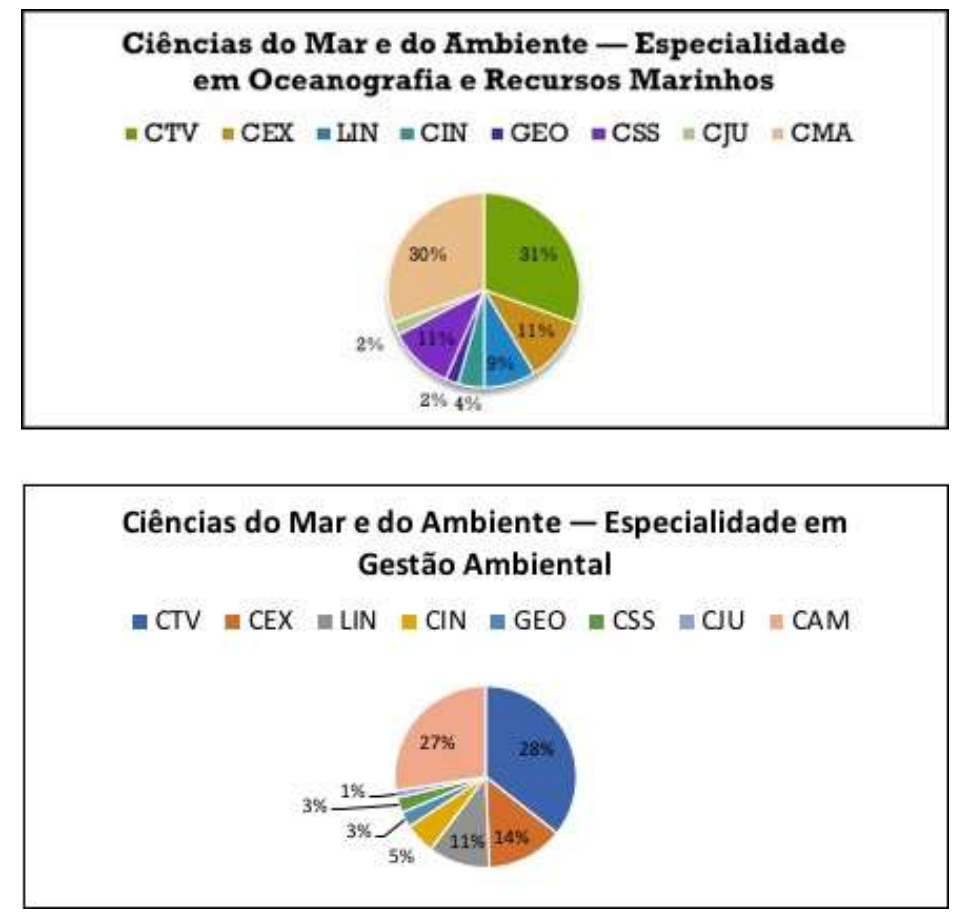

Fig. 2. Percentagem de cada área científica que compõem cada uma das especialidades do curso de CMA. Legenda: CTV - Ciências da Terra e da Vida; CEX- Ciências Exatas; LIN-Línguas; CINCiências Informáticas; GEO- Geografia; CSS- Ciências Sociais; CJU- Ciências Jurídicas; CMACiências do Mar; CAM- Ciências Ambientais (SÁ, 2016, p. 14)

Rev. Eletrônica Mestr. Educ. Ambient. Rio Grande. v. 36, n. 3. Seção especial: V Congresso Internacional de Educação Ambiental dos Países e Comunidades de Língua Portuguesa. p. 336-355. Set/Dez. 2019. 
No último semestre do $4^{\circ}$ ano do curso (i.e. $8^{\circ}$ semestre letivo) os alunos têm obrigatoriamente que apresentar e defender publicamente uma monografia de investigação e um relatório de estágio composto por 300 horas numa instituição de acolhimento sendo tutoreados em ambos os casos por um supervisor. Pedagogicamente o curso de CMA utiliza várias tipologias de ensino: desde as clássicas aulas teóricas, mas também teóricopráticas, laboratoriais ${ }^{3}$ (Fig. 3) conjugadas com saídas de campo e visitas de estudo (Fig. 4). A disciplina de Educação Ambiental está implementada como obrigatória para os estudantes da especialidade de Gestão Ambiental, mas durante a sua formação os estudantes são obrigados a refletir sobre problemáticas glocais. O ensino é complementado com seminários, workshops, palestras, celebração de efemérides e visualização de filmes e documentários (Fig. 5) com uma frequência mensal geralmente proferidas por investigadores que se encontram a realizar trabalho de campo na Guiné-Bissau.

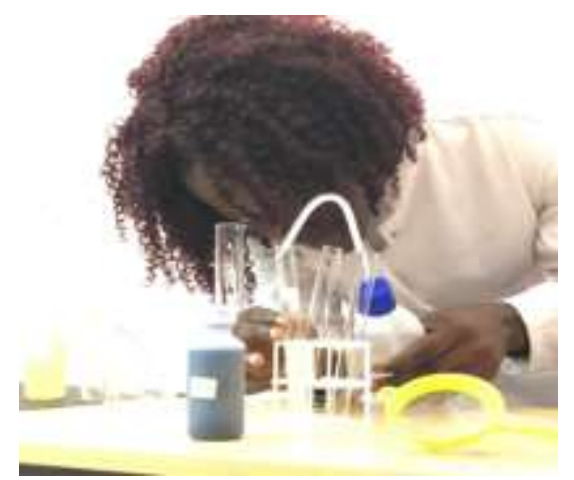

Fig. 3. Uma aluna do curso de CMA a realizar uma experiência laboratorial (2018).

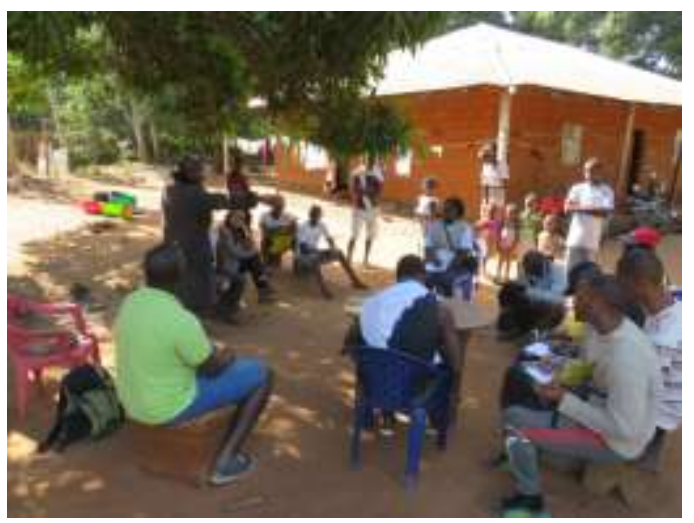

Fig. 4. Saída de campo dos alunos de CMA ao Parque Nacional de Cantanhez (2017) onde aprenderam diretamente com as comunidades locais.

\footnotetext{
${ }^{3}$ Foram criados dois laboratórios de raiz. Um de Biologia e outro de Química para que os alunos possam ter acesso ao ensino experimental.

Rev. Eletrônica Mestr. Educ. Ambient. Rio Grande. v. 36, n. 3. Seção especial: V Congresso Internacional de Educação Ambiental dos Países e Comunidades de Língua Portuguesa. p. 336-355. Set/Dez. 2019. 
O curso conta atualmente com cerca de 300 estudantes, e o ensino é assegurado por 40 docentes nacionais e internacionais, especialistas nas diversas áreas científicas, onde a maioria possui o grau de Mestre. Dezassete (17) estudantes obtiveram a sua graduação em 2019 constituindo a primeira geração de licenciados, onde alguns deles já se encontram inseridos no mercado de trabalho.

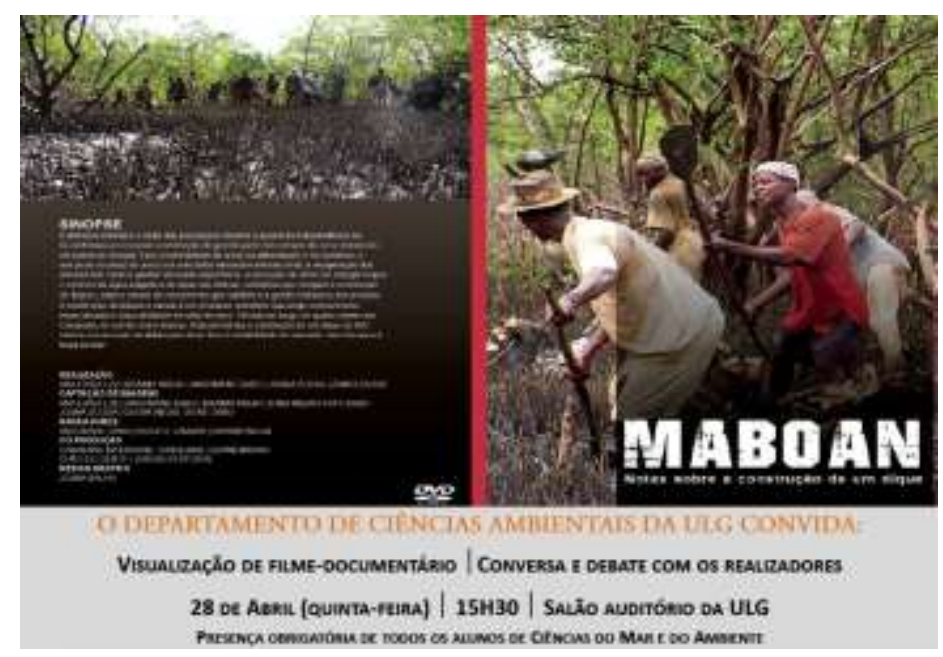

Fig. 5. Mostra de um documentário (2016).

\section{Atividades de investigação, intercâmbio e extensão}

O curso de CMA tem uma forte componente de investigação e os estudantes ao longo do seu percurso são fortemente encorajados em colaborar junto dos seus docentes em projetos de pesquisa. Um dos projetos que está a ser conduzido no departamento de Ciências Ambientais da ULG desde 2016 é o Projeto Herbário (Fig.6). Depois da guerra civil de 7 de Junho de 1998 a Guiné Bissau perdeu muito dos seus acervos documentais e bibliográficos. Não existia no país nenhum herbário nacional que permitisse estudar in loco a flora e a vegetação guineense. Os espécimes que existem estão depositados no herbário da Universidade de Coimbra ou no depósito do antigo Instituto de Investigação Científica Tropical. Era por isso necessário começar a fazer um levantamento dos principais exemplares botânicos da Guiné-Bissau que servisse por um lado como método didático, mas também para fins de estudos de sistemática e taxonomia vegetal. Neste projeto estão envolvidos 4 alunos bolseiros que trabalham na manutenção do acervo, nas recolhas, saídas de campo, identificação e incorporações. O acervo conta atualmente com cerca de 220 espécies identificadas. A ULG tem uma revista científica de acesso livre com o nome

Rev. Eletrônica Mestr. Educ. Ambient. Rio Grande. v. 36, n. 3. Seção especial: V Congresso Internacional de Educação Ambiental dos Países e Comunidades de Língua Portuguesa. p. 336-355. Set/Dez. 2019. 
Sintidus onde parte do seu conselho editorial pertence ao departamento de Ciências Ambientais e onde alguns docentes publicam as suas pesquisas (SINTIDUS 2019).

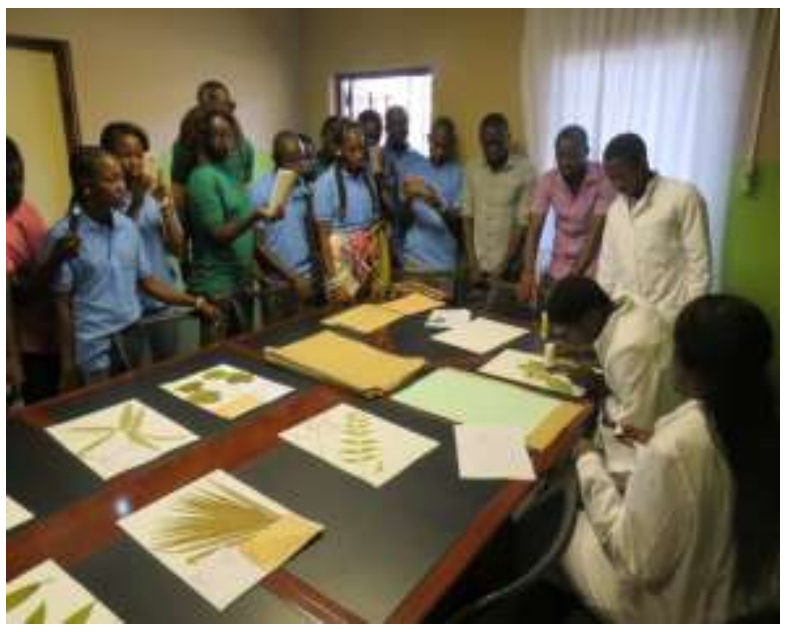

Fig. 6. Visita de estudantes ao Projeto Herbário (2017).

O curso de CMA tem igualmente protocolos de colaboração com universidades internacionais onde recebe alguns alunos estrangeiros ao nível do mestrado por forma fomentar a interculturalidade e promoção dos direitos humanos (Fig. 7).

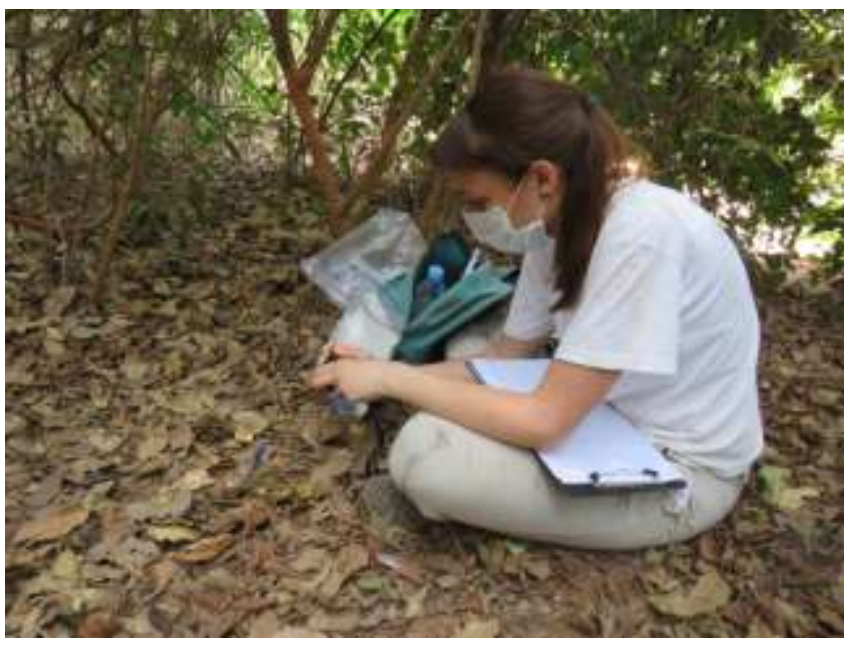

Fig. 7. Uma aluna italiana da Universidade de Pisa em intercâmbio científico a realizar trabalho de campo em Nova Sintra (2017).

A ligação à sociedade e às comunidades locais realiza-se através de atividades de extensão. $\mathrm{O}$ curso de CMA tem estado engajado em facilitar o acesso à ciência e promovêla como um Direito Fundamental tal como está inscrito no Art.o 27 da Declaração Universal dos Direitos Humanos (1948): "Toda a pessoa tem o direito de tomar parte livremente na vida cultural da comunidade, de fruir as artes e de participar no progresso

Rev. Eletrônica Mestr. Educ. Ambient. Rio Grande. v. 36, n. 3. Seção especial: V Congresso Internacional de Educação Ambiental dos Países e Comunidades de Língua Portuguesa. p. 336-355. Set/Dez. 2019. 
científico e nos beneficios que deste resultam.". Para além disso realiza e participa com frequência jornadas de sensibilização ambiental (Fig. 8 e 9).

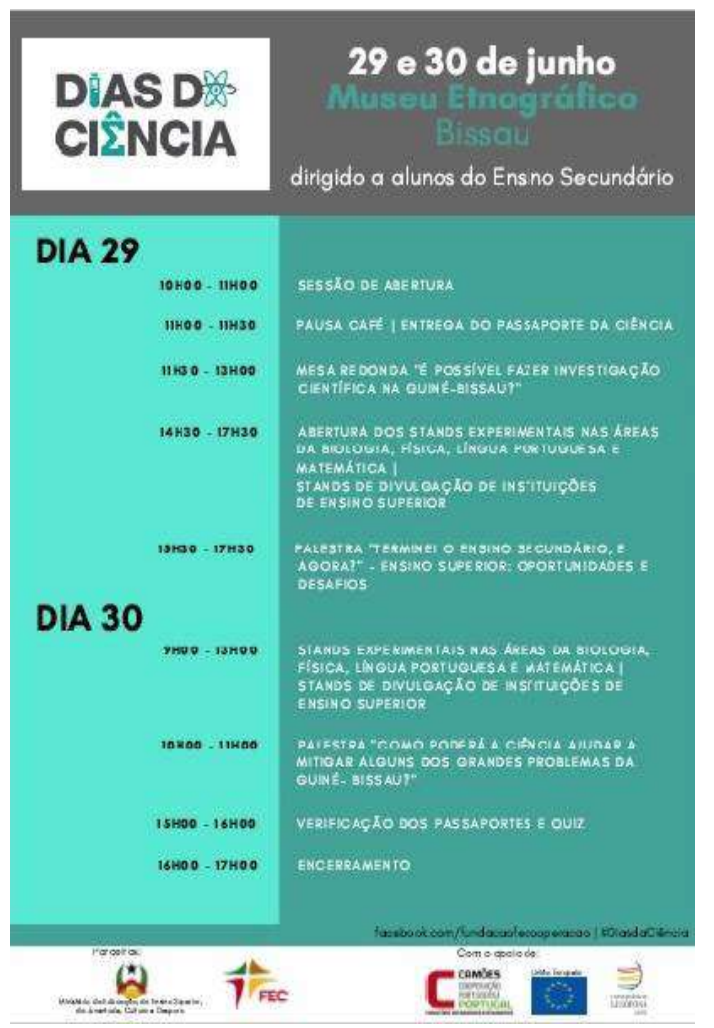

Fig. 8. Organização dos Dias da Ciência (2018).

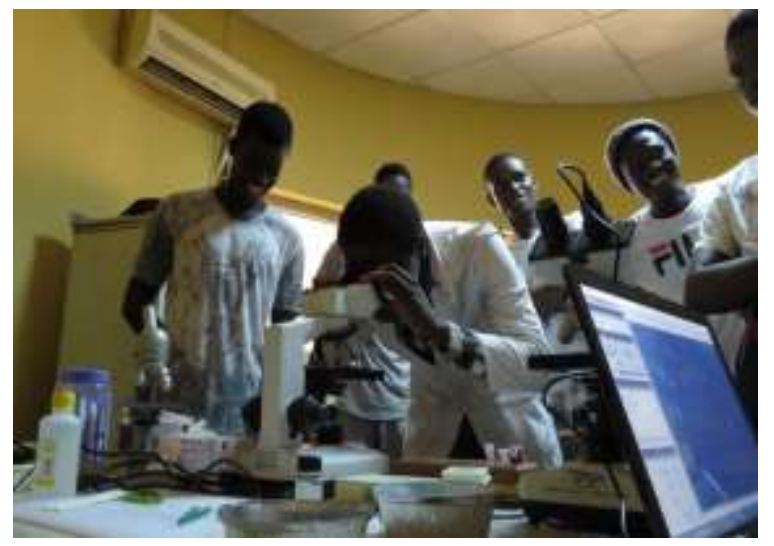

Fig. 9. Conjunto de alunos que tiveram acesso pela primeira vez a um microscópio e a experiências de Biologia Celular.

Como forma de extensão foi também criado o Projeto Imanências. Trata-se de um projeto artístico que pretende dar a conhecer a riqueza cultural e ambiental que a GuinéBissau tem. Já foi apresentado em Viseu e no Porto em Portugal e na ilha de Canhabaque na Guiné-Bissau (Fig. 10 e 11).
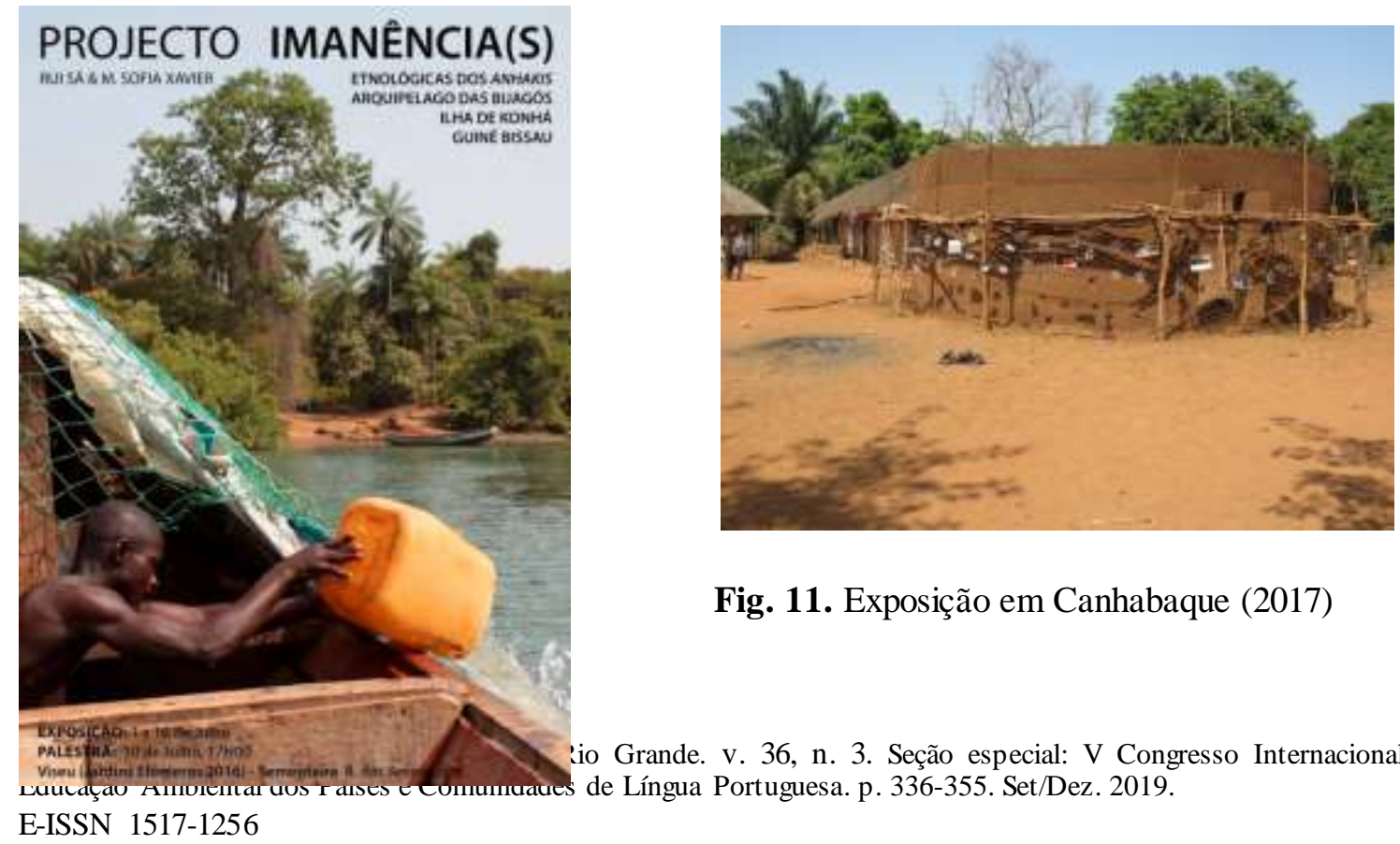

Fig. 11. Exposição em Canhabaque (2017) 
Fig. 10. Exposição em Portugal (2016)

\section{Perceção e satisfação do curso de CMA por parte dos estudantes}

Por forma a aferir o nível de satisfação que os estudantes têm com o curso de CMA foi aplicado um questionário a $(\mathrm{N}=78)$ estudantes. Em termos de caracterização da amostra $73 \%(\mathrm{n}=57)$ pertencem ao sexo Masculino, 22\% $(\mathrm{n}=17)$ ao sexo Feminino e cerca de 5\% $(\mathrm{n}=4)$ optaram por não responder. Relativamente à variável Idade, a média situa-se nos 23 anos (SD: \pm 6.269 ) onde o aluno mais novo indicou ter 18 anos e o aluno com mais idade cerca de 49 anos. Mais de metade dos alunos $(54 \%, \mathrm{n}=42)$ indicou ser trabalhador estudante e $47 \%(n=37)$ é natural de Bissau.

Em termos gerais, a maioria dos estudantes inquiridos está satisfeita $(44 \%, \mathrm{n}=34)$ ou muito satisfeita $(50 \%, n=38)$ com o curso de CMA (Fig. 11). Para que o seu grau de satisfação seja de Muito Satisfeito alguns estudantes destacam os seguintes aspetos: Aluno \#1: "Mais bolsas de estudo"; Aluno \#2: "Mais recursos da biblioteca"; Aluno \#3: "Mais saídas de campo e trabalho no laboratório"; Aluno \#4: "Melhor rede de Internet", Aluno \#5: "Melhorar o atendimento em alguns serviços na universidade".

Quando questionados sobre a forma como foi divulgado o curso 55\% diz que está muito satisfeita e $43 \%$ satisfeita (Fig. 12). Sobre os métodos de ensino utilizados 59\% $(\mathrm{n}=41)$ diz que está satisfeita e 16\% (n=11) que está insatisfeita (Fig.13). Sobre o plano curricular $60 \%(\mathrm{n}=47)$ dizem que o mesmo deveria ser mantido, 15\%(n=12) afirma que seria necessário aumentar mais disciplinas e somente $12 \%$ afirma que o número de disciplinas deveria ser reduzido (Fig. 14).

Em traços gerais o curso de CMA está a corresponder com as expetativas dos estudantes, embora sejam frequentemente mencionadas algumas dificuldades no que respeita a algumas disciplinas como é o caso das Químicas. Esse facto pode dever-se sobretudo à qualidade de ensino ministrada no ensino secundário onde os alunos sentem que lhes faltam algumas bases que já deveriam estar consolidadas. As disciplinas com as quais têm mais afinidade prendem-se com aquelas da sua área de interesse de especialidade: sejam as disciplinas mais vocacionadas para a oceanografia como aquelas mais dirigidas para a gestão dos recursos ambientais. Esta pequena avaliação sobre o grau de satisfação dos alunos não pretendeu ser exaustiva. $\mathrm{O}$ objetivo era fazer um ponto de situação relativamente à perceção que os próprios estudantes tinham sobre o curso de 
CMA por forma a melhorar alguns aspetos. Um dado relevante que merece a pena ser destacado é a percentagem de alunos que indica ser necessário aumentar o número de disciplinas. Este parece ser um indicador indireto da motivação dos estudantes para aprender e aprofundar outras ou novas áreas do conhecimento.

\section{Grau de satisfação global com o curso de CMA}

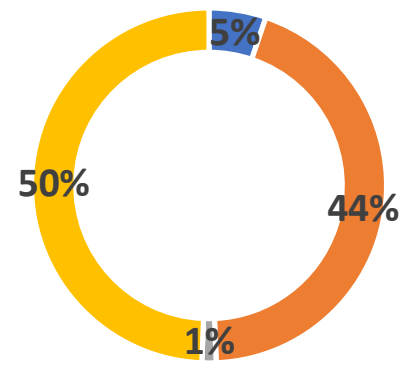

— Insatisfeito $\square$ Satisfeito $\square$ Nem satisfeito/ Nem insatisfeito $\square$ Muito satisfeito

Fig. 11: Nível de satisfação dos estudantes com o curso de CMA.

\section{Grau de satisfação relativamente à divulgação do curso de CMA}

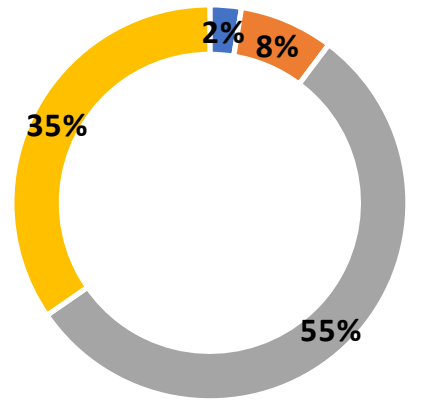

- Muito Insatisfeito $\quad$ Instisfeito $\quad$ Satisfeito $\square$ Muito satisfeito

Fig. 12: Nível de satisfação dos estudantes com a divulgação do curso de CMA. 


\section{Grau de satisfação relativamente aos métodos de ensino}

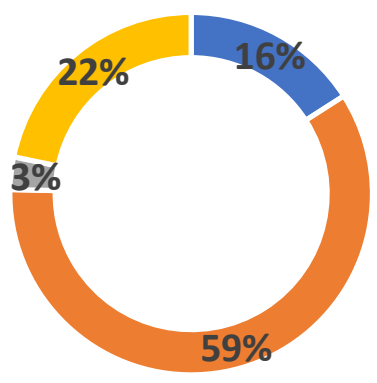

- Insatisfeito $\square$ Satisfeito $\backsim$ Nem satisfeito/ Nem insatisfeito $\square$ Muito satisfeito

Fig. 13: Nível de satisfação dos estudantes com as diferentes tipologias de ensino usadas no curso de CMA.

\section{Grau de satisfação com o Plano Curricular}

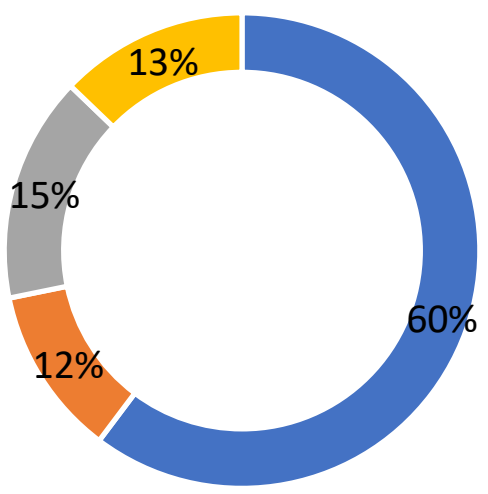

Manter $\square$ Diminuir $\square$ Aumentar $\square$ NS/NR

Fig. 14: Nível de satisfação com o plano curricular do curso de CMA.

\section{CONSIDERAÇÕES FINAIS}


O curso de CMA foi a primeira formação de nível superior nos domínios do mar e do ambiente a ser implantado na Guiné-Bissau. Pretende formar profissionais e técnicos qualificados no seu próprio país através de um ensino dirigido para as problemáticas nacionais ao invés de importar um modelo exterior ou de se basear no envio de bolseiros para adquirem a sua formação a nível externo onde muitos acabam por não regressar. $\mathrm{O}$ curso recolheu o apoio institucional de diversas organizações apesar das vicissitudes políticas e sociais da Guiné-Bissau e este esforço de colaboração tem sido muito positivo e quiçá a sua imagem de marca. Do ponto de vista dos alunos o curso de CMA tem vindo a corresponder às suas expetativas e o quinquénio 2014-2019, o período mais crucial: desde a sua criação até ao seu estabelecimento foi bem-sucedido. O curso tem uma ligação muito forte à Educação Ambiental e talvez seja essa uma das suas chaves para o seu reconhecimento. A Guiné-Bissau oferece muitas possibilidades de sucesso em educação ambiental não só porque detém uma população muito jovem que com os efeitos globalizantes está a par das grandes problemáticas ambientais, mas também porque a maior parte dos recursos utilizados pelas comunidades humanas advém dos serviços prestados pelos ecossistemas: é necessário criar oportunidades e experimentar fórmulas locais dando relevância aos saberes e conhecimentos ecológicos tradicionais. Os novos desafios que o curso de CMA irá enfrentar será dirigir um nível de formação específico para professores do $1^{\circ}$ ciclo ao ensino secundário em Ambiente e Cidadania e criar um projeto de ciência cidadã e itinerante que visitará as escolas do interior da Guiné-Bissau, colocando as crianças, os jovens e os adultos a observar e a experimentar mediados pelos estudantes do próprio curso de CMA.

\section{AGRADECIMENTOS}

O autor gostaria de agradecer à direção da ULG por ter arriscado e investido nesta formação. Ao Sr. Ussumane Baldé, Rosa da Silva e Paulo Indi Sambu pela ajuda na aplicação dos questionários e a todos os alunos que se disponibilizaram a dar a sua opinião. Ao Instituto da Biodiversidade e das Áreas Protegidas da Guiné-Bissau pelo apoio incondicional ao longo dos anos e a todos os colegas docentes do Departamento de Ciências Ambientais que de uma forma direta contribuíram para que este projeto fosse uma realidade.

Relativamente à redação do artigo este trabalho é financiado por fundos nacionais através da FCT- Fundação para a Ciência e Tecnologia, I.P. no âmbito da celebração do 
contrato-programa previsto nos números 4,5 e 6 do art $^{\circ} 23^{\circ}$ do D.L. no 57/2006 de 29 de agosto, alterado pela Lei $\mathrm{n}^{\circ} 57 / 2017$, de 19 de Julho.

\section{REFERÊNCIAS}

AUGEL, Moema Parente. A nova literatura da Guiné-Bissau. Bissau: INEP, 1998. Coleção Kebur.

AUKEMA, Juliann, et al. Biodiversity áreas under threat: overlap of climate change and population pressures on the World's priorities. PLOS ONE, V. 12, n. 1, 2017, p. 1-21.

ASONGU, Simplice, e TCHAMYOU, Vanessa. Foreign aid, education and lifelong learning in Africa. Journal of Knowledge Economy, V. 10, n.1 2019, p. 126-146.

BANCO MUNDIAL. Government expenditure on education as \% of GDP, 2016. < https $/ /$ data. worldbank.org/ind ic ator/SE.XPD.TOTL.GD.ZS? locations=GW> Acesso em: 04 Ago. 2019.

CÁCERES, V.M. et al. Daily zero-reporting for suspect Ebola using short message servive (SMS) in Guinea-Bissau. Public Health, V. 138, 2016, p. 69-73.

CHICA, A. Alaminos, e COSTA, Castejón. Elaboración, análisis e interpretación de encuestas, cuestionários y escalas de opinión. Alicante: 2006, Universidad de Alicante. $<$ https://rua.ua.es/dspace/bitstream/10045/20331/1/Elaboraci\%c3\%b3n,\%20an\%c3\%a1 lisi s\%20e\%20interpretaci\%c3\%b3n.pdf> Acesso em: 10 Jul. 2019.

CHIKOUNA, Cissé. Le CAMES 1968-2018. Um demi-siècle au servisse de l'enseigment supérieur et de la recherche em Afrique. Ouadougou: 2018, CAMES.

DECLARAÇÃO UNIVERSAL DOS DIREITOS HUMANOS. Art. ${ }^{\mathbf{2}} \mathbf{2 7}^{\mathbf{0}}$. 1948. Nações Unidas. Disponível em: < https://dre.pt/declaracao-universal-dos-direitos-humanos> Acesso em 02 Ago 2019.

DN- DIÁRIO DE NOTÍCIAS. Ativista ambiental da Guiné-Bissau considera criminosa a venda de madeira decretada pelo governo. 2018. Disponível em: $<$ https://www.dn.pt/lusa/interior/ativista-ambiental-da-guine-bissau-considera-criminosavenda-de-madeira-decretada-pelo-governo-9074295.html> Acesso em : 04 Ago. 2019.

DW-DEUTSCHE WELLE. Petição internacional quer o fim da desflorestação ilegal na Guiné-Bissau. 2014. Disponível em: <https://www.dw.com/pt002/peti\%C3\%A7\%C3\%A3o-internacional-quer-o-fim-dadesfloresta\%C3\%A7\%C3\%A3o-ilegal-na-guin\%C3\%A9-bissau/a-17719512> Acesso em 04 Ago. 2019.

DW-DEUTSCHE WELLE. Mais de mil milhões de euros para a Guiné-Bissau na mesa redonda de Bruxelas. DW. 2015. <https://www.dw.com/pt-002/mais-de-milmill \%C3\%B5es-de-euros-para-a-guin\%C3\%A9-bissau-na-mesa-redonda-de-bruxelas/a18341843> Acesso em: 03 Ago. 2019.

Rev. Eletrônica Mestr. Educ. Ambient. Rio Grande. v. 36, n. 3. Seção especial: V Congresso Internacional de Educação Ambiental dos Países e Comunidades de Língua Portuguesa. p. 336-355. Set/Dez. 2019. 
EU- European Union External Action. Terra Ranka: a fresh start for Guinea-Bissau. Disponível em: <https://eeas.europa.eu/generic-warning-systemtaxonomy/404_en/2105/Terra\%20Ranka:\%20A\%20Fresh\%20Start\%20for\%20GuineaBissau> Acesso em: 03 Ago. 2019.

FILHO, W. Leal et al. The role of transformation in learning and education for sustainability. Journal of cleaner production, V. 199, 2018, p.286-295.

GEBREMICHAEL, Mesfin et al. (Org.) Guinea-Bissau. Conflict Insight. Addis Ababa: Institute for Peace and Security Studies, 2019.

GYIMAH-BREMPONG, Kwabena, PADDISON, Oliver, MITIKU, Workie. Higher education and economic growth in Africa. The Journal of Development Studies, V. 42, n. 3, 2006, p. 509-529.

HAMMERSLEY, Martyn e ATKINSON, Paul. Etnografía. Métodos de investigación. Barcelona: 2001, Paidós.

INASA. As evidências sobre a relação entre animaios e Ebola provocaram um desafio nacional na Guiné-Bissau. 2017. 〈http://inasagb.org/index.php/pt/saude-unica/> Acesso em: 07 Ago 2019.

INTCHAMA, Francisco Jereminas, BELHABIB, Dyhia e JUMPE, Raul Joaquim Tomás. Assessing Guinea-Bissau's Legal and Illegal Unreported and Unregulated Fisheries and the surveillance efforts to tackle them. Frontiers in Marine Science, V. 5, 2018, p. 1-11.

KOHL, C. Ethnicity and the Political System Post-1998. Em Chabal, P. e Green, T. (Org.) Guinea-Bissau: Micro-State to "Narco-State". London, 2016, Hurst and Company (p.161-184).

LUNDY, Brandon D. Rebuilding tertiary education in Guinea-Bissau: can it be done? FIRE: Forum for International Research in Education, V. 4, n. 3, 2018, p. 169-190.

OKOLIE, Andrew C. Producing knowledge for sustainable development in Africa: implications for higher education. Higher Education, V. 46, 2003, p. 235-260.

PIOT, Peter, MUYEMBE, Jean-Jacques, Edmunds, W.John. Ebola in West Africa: from disease oubreak to humanitarian crisis. The Lancet Infectious Diseases, V. 14, 2014, p. 1034-1035.

RGB- REPÚBLICA DA GUINÉ-BISSAU. Lei do Ensino Superior e da Investigação Ciêntífica. Boletim Oficial. Bissau, 2011.

SÁ, Rui M. M. Primatologia molecular. Contributo para a Conservação de um grupo de chimpanzés (Pan troglodytes verus) da República da Guiné-Bissau. Diversidade mitocondrial, sexagem e aplicações forenses. Dissertação de Mestrado, Coimbra, 2011: Universidade de Coimbra. 
SÁ, Rui M. M. Phylogeography, conservation genetics and parasitology of chimpanzees (Pan troglodytes verus) in Guinea-Bissau, West Africa. Tese de Doutoramento, Lisboa, 2013: Universidade Nova de Lisboa.

SÁ. Rui M. M. Guia de curso de Ciências do Mar e do Ambiente, Bissau: Universidade Lusófona da Guiné, 2016, Edições ULG, p.1-167.

SANI, Quecoi, OLIVEIRA, Marlize Rubin. Educação Superior e Desenvolvimento na Guiné-Bissau. Contribuições, Limites e Desafios. Revista Pedagógica, V.16, 2004, p.127152.

SILVA, R. e OLIVEIRA, J. 40 years of educational research in Guinea-Bissau: Mapping the terrain. International Journal of Educational Development, V. 57, 2017, p. 21-29.

SINTIDUS. 2019. Disponível em: <http://sintidus.blogspot.com/> Acesso em: 05 Ago. 2019.

SUCUMA, Arnaldo. A participação do Estado e ensino superior no processo de desenvolvimento da Guiné-Bissau. $3^{\mathbf{o}}$ Encontro Internacional de Política Social e $\mathbf{1 0}^{\mathbf{o}}$ Encontro Nacional de Política Social, Vitória 22 a 25 de Junho, 2015 p. 1-14. < http://periodicos.ufes.br/EINPS/article/view/9958/6961> Acesso em: 02 Ago. 2019.

TEMUDO, Marina, FIGUEIRA, Rui, ABRANTES, Manuel. Landscapes of bio-cultural diversity: shifting cultivation in Guinea-Bissau, West Africa. Agroforestry Systems, V. 89, n.1, 2015, p.175-191.

UNDP- United Nations Development Program. Os objetivos de desenvolvimento sustentável, 2016. Disponível em: <

https $/ /$ www.undp.org/content/undp/en/home/sustainable-development-goals.html > Acesso em: 04 Ago. 2019.

UNDP- United Nations Development Program. Human Development Reports: GuineaBissau 2017. < http:/hdr.undp.org/en/countries/profiles/GNB> Acesso em: 04 Ago. 2019.

UNIOGBIS. WFD: Guinea-Bissau forests still at risk despite good protection system. 2017. Disponível em: <https://uniogbis.unmissions.org/en/wfd-guinea-bissau-forests-stillrisk-despite-good-protection-system> Acesso em: 04 Ago. 2019.

VASCONCELOS, Sasha et al. Through the eye of a butterfly: Assessing biodiversity impacts of cashew expansion in West Africa. Biological Conservation, V. 191, 2015, p. 779-786. 